Scientific Review - Engineering and Environmental Sciences (2017), 26 (2), 193-201

Sci. Rev. Eng. Env. Sci. (2017), 26 (2)

Przegląd Naukowy - Inżynieria i Kształtowanie Środowiska (2017), 26 (2), 193-201

Prz. Nauk. Inż. Kszt. Środ. (2017), 26 (2)

http://iks.pn.sggw.pl

DOI 10.22630/PNIKS.2017.26.2.17

Piotr JAŚKOWSKI, Michal TOMCZAK

Katedra Inżynierii Procesów Budowlanych, Politechnika Lubelska

Department of Construction Methods and Management, Lublin University of Technology

\title{
Problem minimalizacji przestojów w pracy brygad generalnego wykonawcy $w$ harmonogramowaniu przedsięwzięć budowlanych ${ }^{*}$ Minimisation of work gaps for general contractor crews in construction project scheduling
}

Slowa kluczowe: harmonogramy budowlane, zarządzanie $\mathrm{w}$ budownictwie, modele sieciowe, ciagłość realizacji procesów, wybór podwykonawców

Key words: construction project schedule, construction project management, network model, continuity of processes, subcontractors' selection

\section{Wprowadzenie}

Tradycyjne podejście do harmonizacji procesów budowlanych koncentruje się na minimalizacji czasu trwania przedsięwzięcia i/lub kosztu jego realizacji. Klasyczne metody harmonogramowania (metody sieciowe CPM, PERT, PD) są szeroko krytykowane w literaturze (Biruk i Jaśkowski, 2009; Elbeltagi i Ammar, 2001; Vanhoucke, 2006; Damci, Arditi i Polat, 2013; Zhang, Zou i Su, 2013). Jako główne słabości tych metod wymienia się m.in. (Damci i inni, 2013; Elbeltagi i Ammar, 2001; Zhang i inni, 2013): trudności w modelowaniu przedsięwzięć $\mathrm{z}$ dużą liczbą procesów, nieuwzględnianie ograniczeń w dostępności zasobów, złożoność modelowania procesów powtarzalnych i ciagłości realizacji procesów oraz przepływu zasobów. Ze względu na te niedoskonałości rozwijane są metody harmonogramowania zorientowane na zasoby (Damci i inni, 2013) $z$ uwzględnieniem ograniczeń $w$ ich dostępności oraz ciagłości ich pracy.

Zapewnienie ciagłości pracy zasobów oraz pełne wykorzystanie ich po-

*Wyniki prac były finansowane ze środków statutowych przyznanych przez Ministerstwo Nauki i Szkolnictwa Wyższego (S/63/2017). 
tencjału produkcyjnego jest podstawową intencją metod potokowych oraz znanych z literatury anglojęzycznej metod: LOB (ang. Line of Balance) i LSM (ang. Linear Scheduling Method). Harris i Ioannou (1998) opracowali metodę RSM (ang. Repetitive Scheduling Method), która jest rozwinięciem metody drogi krytycznej dla przedsięwzięć zawierających powtarzalne procesy. Metoda ta umożliwia uwzględnienie ograniczeń technologicznych, zapewnia ciagłość pracy brygad oraz pozwala zidentyfikować kontrolny ciąg czynności (ang. contolling sequence) wpływający na termin realizacji całego przedsięwzięcia, który jest odpowiednikiem ścieżki krytycznej w metodzie CPM. Alternatywny algorytm identyfikacji ciagu kontrolnego przy nieustannej realizacji procesów opracowali Elbeltagi i Ammar (2001). Wang, Wang i He (2013) opracowali model matematyczny przydziału zasobów do realizacji procesów powtarzalnych z uwzględnieniem ograniczeń w ich dostępności oraz warunku ciagłości ich zatrudnienia. Ponieważ analizowany problem jest NP-trudny, autorzy do rozwiązania modelu zastosowali algorytm genetyczny. Algorytm minimalizacji przestojów pracy brygad realizujących procesy powtarzalne zaproponowal Vanhoucke (2006).

Planując realizację przedsięwzięć budowlanych typu kompleks operacji, korzysta się powszechnie z metod sieciowych. Nowicki (1981) przedstawił sposób analizy modeli sieciowych (ustalania terminów realizacji) zapewniający ciagłość realizacji robót przy ustalonym terminie końcowym przedsięwzięcia. Wyróżnił w modelu dwa typy zdarzeń: spełniające warunek poprzedzania oraz poprzedzania i ciagłości. Vanhoucke i Debels (2007) zaproponowali inne podejście, umożliwiające minimalizację przerw na drogach, dla których dąży się do zapewnienia ciagłości realizacji. W tym celu na początku i końcu każdej takiej drogi (złożonej z procesów, które mogą być realizowane różnymi wariantami technologiczno-organizacyjnymi) wprowadzili dwie sztuczne czynności połączone z początkowym i końcowym wierzchołkiem sieci. Wydłużanie czasów czynności sztucznych powoduje - przy ustalonym w kontrakcie terminie końcowym przedsięwzięcia - redukcję przerw na drodze ciagłej. Ideę czynności sztucznych wykorzystali Biruk i Jaśkowski (2009) w celu poszukiwania kompromisu między czasem realizacji przedsięwzięcia a czasem przerw w realizacji szczegółowych ciągów organizacyjnych przez brygady robocze.

Ponieważ harmonizacja pracy brygad i zespołów roboczych jest kluczowym zagadnieniem inżynierii przedsięwzięć budowlanych (Georgy, 2008; Biruk i Jaśkowski, 2009; Tang, Liu i Sun, 2014), istnieje wiele badań i opracowań na ten temat. Jednak większość z nich dotyczy harmonogramowania przedsięwzięć składających się z procesów powtarzalnych oraz nie uwzględnia możliwości zatrudnienia podwykonawców, pomimo że według badań Grasso, Rasdorfa i Bridgersa (2008) nawet $76,1 \%$ procesów budowlanych jest zlecanych do realizacji innym podmiotom przez generalnych wykonawców.

W artykule opracowano model programowania liniowego dla przedsięwzięcia budowlanego typu kompleks operacji, zapewniający minimalizację przerw w pracy brygad generalnego wykonawcy 
z uwzględnieniem ograniczeń $\mathrm{w}$ dostępności wykonawców oraz z możliwością zlecania wykonania procesów podwykonawcom. Możliwość podwykonawstwa robót nie pozwala na jednoznaczne wskazanie w modelu przedsięwzięcia ciagów procesów realizowanych przez brygady i zastosowanie dotychczas opracowanych metod harmonogramowania.

\section{Model matematyczny problemu minimalizacji przestojów brygad głównego wykonawcy}

Przedsięwzięcie budowlane jest modelowane za pomocą sieci sporządzonej techniką jednopunktowa. Zakres przedsięwzięcia (podział na pakiety czy poszczególne procesy - pozycje w harmonogramie) oraz zależności kolejnościowe są przedstawione za pomoca grafu $G=\langle V, E\rangle$, z jednym wierzchołkiem początkowym i końcowym, w którym $V=\{1,2, \ldots, n\}$ jest zbiorem procesów, a łuki grafu $E \subset V \times V$ odzwierciedlają relacje kolejnościowe między procesami.

Do realizacji przedsięwzięcia moga być zaangażowani wykonawcy (lub brygady) ze zbioru $R$ obejmującego $R_{G W}$ podzbiór brygad generalnego wykonawcy $(G W)$ oraz $R_{P}$ podzbiór podwykonawców. Dla każdego procesu $j \in V$ jest określony zbiór $R_{j} \subset R$ obejmujący dostępnych wykonawców. Dla każdego wykonawcy $r \in R$ można określić zbiór procesów $V_{r} \subset V$, do realizacji których może być on przydzielony. Wykonawca $r \in R_{j}$ będzie realizować proces $j$ w czasie $t_{j, r} \in N \mathrm{z}$ kosztem $k_{j, r} \in R^{+}$. Zmienne $s_{j}, \forall j \in V$ oznaczają terminy rozpoczęcia procesów. Decyzje o wyborze wykonawców do realizacji procesów są mode- lowane za pomocą zmiennych binarnych $x_{j, r} \in\{0,1\}$. Zmienna $x_{j, r}$ przyjmie wartość 1 , gdy proces $j$ będzie realizowany przez wykonawcę $r$, a wartość $0 \mathrm{w}$ przeciwnym przypadku.

Niektórzy wykonawcy mogą realizować kilka procesów (pakietów robót), lecz nie jednocześnie. $Z$ tego względu dla każdego wykonawcy $r \in R$ należy określić zbiór par procesów $J_{r} \subset V \times$ $\times V$ spełniających następujące warunki: $(u, v) \in J_{r} \Leftrightarrow u \in V_{r} \wedge v \in V_{r} \wedge u<v$ (procesy $u$ i $v$ mogą być realizowane przez wykonawcę $r$ ), a procesy $u$ i $v$ nie leżą na jednej drodze w modelu sieciowym. W przypadku gdy do realizacji pary procesów $(u, v) \in J_{r}$ zostanie przydzielony wykonawca $r\left(x_{u, r}=1 \wedge x_{v, r}=1\right)$ procesy te nie mogą być wykonane równocześnie (równolegle). Kolejność realizacji tych procesów będzie modelowana za pomoca zmiennych binarnych $y_{u, v} \in\{0,1\}$, określonych dla $\forall(u, v) \in J_{r}$ oraz dla $\forall r \in R$. Zmienna $y_{u, v}$ przyjmie wartość 1 , jeżeli proces $u$ będzie zrealizowany przed rozpoczęciem procesu $v$, wartość $0 \mathrm{w}$ przeciwnych przypadku.

Dobór wykonawców procesów oraz ustalenie terminów ich wykonania będzie dokonywany w sposób zapewniający redukcję przestojów w pracy brygad generalnego wykonawcy. Łączny czas przestojów w pracy każdej brygady będzie obliczany jako różnica terminów rozpoczęcia pracy danej brygady przy realizacji analizowanego przedsięwzięcia, zakończenia jej pracy i łącznego czasu wykonania powierzonych jej do wykonania procesów. Aby ustalić niezbędne terminy, w modelu dla każdej brygady $G W r \in R_{G W}$ i dla każdego procesu $j \in V_{r}$, który może ona realizować, zastosowano dodatkowe zmienne w postaci: 
$p_{j, r}=s_{j} \cdot x_{j, r}, \quad \forall r \in R_{G W}, \forall j \in V_{r}$

(1)

W przypadku gdy proces $j$ będzie realizowany przez brygadę $r$, zmienna $p_{j, r}$ przyjmie wartość równą terminowi rozpoczęcia realizacji procesu $j$, w przeciwnym przypadku wartość 0 . Ze względu na nieliniowy charakter zależności (1), w modelu zastapiono ją dodatkowymi zależnościami liniowymi, co umożliwiło zastosowanie do rozwiązania modelu istniejących algorytmów programowania liniowego o mniejszej złożoności obliczeniowej.

Model zagadnienia wyboru wykonawców poszczególnych procesów i ustalenia terminów ich wykonania (przy ustalonym dyrektywnie czasie $T$ i koszcie $K$ realizacji przedsięwzięcia oraz ustalonym granicznym $K_{g P}$ koszcie robót zleconych podwykonawcom) przyjmuje następującą postać:

$\min P: P=$

$=\sum_{r \in R_{G W}}\left(z_{r}^{\max }-s_{r}^{\min }-\sum_{j \in V_{r}}\left(t_{j, r} \cdot x_{j, r}\right)\right)$

$D_{j}=\sum_{r \in R_{j}} t_{j, r} \cdot x_{j, r}, \quad \forall j \in V$

$\sum_{r \in R_{j}} x_{j, r}=1, \quad \forall j \in V$

$s_{1}=0$

$s_{i}+D_{i} \leq s_{j}, \quad \forall(i, j) \in E$

$s_{u}+D_{u} \leq s_{v}+M \cdot\left(1-y_{u, v}\right)+$

$+M \cdot\left(2-x_{u, r}-x_{v, r}\right)$

(7) $x_{j, r} \in\{0,1\}, \quad \forall j \in V, \quad \forall r \in R_{j}$

$\forall(u, v) \in J_{r}, \forall r \in R$ 
$y_{u, v} \in\{0,1\}, \forall(u, v) \in J_{r}, \forall r \in R$

gdzie:

$M$ - dostatecznie duża liczba,

$z_{r}^{\max }, s_{r}^{\min }-$ odpowiednio maksymalny termin zakończenia i minimalny termin rozpoczęcia wykonywania procesów powierzonych do wykonania wykonawcy $r$; terminy te odpowiadają terminom zakończenia i rozpoczęcia pracy brygad $G W$ przy realizacji analizowanego przedsięwzięcia,

$z_{j, r}, s_{j, r}-$ zmienne pomocnicze oznaczające odpowiednio termin zakończenia i rozpoczęcia realizacji procesu $j$ przez brygadę $r$; terminy te przyjmują wartość 0 , gdy brygada $r$ nie realizuje procesu $j$.

Funkcja celu (2) minimalizuje łączny czas przestoju w pracy brygad generalnego wykonawcy. Za pomocą równania (3) jest obliczany czas wykonania $D_{j}$ procesu $j$-zmienne tego typu wprowadzono dodatkowo w celu uproszczenia zależności (6)-(9). Zgodnie z warunkiem (4) każdy proces może być wykonany tylko przezjednego wykonawcę. Pierwszy proces rozpoczyna się w terminie 0 (5). Warunek (6) umożliwia wyznaczenie terminów rozpoczęcia pozostałych procesów, z uwzględnieniem zależności kolejnościowych między procesami modelowanych za pomoca grafu $G$. Zależności (7) i (8) umożliwiają wyznaczenie terminów rozpoczęcia procesów $(u, v) \in J_{r}$, które nie moga być realizowane równolegle przez tego samego wykonawcę. Jeżeli do ich wykonania nie zostanie przydzielony ten sam wykonawca $r\left(x_{u, r} \cdot x_{v, r}=0\right)$, wówczas warunki (7) i (8) są zawsze spełnione, a procesy te moga być wykonywane równocześnie. $\mathrm{W}$ przeciwnym przypadku, jeżeli zmienna $y_{u, v}$ przyjmie wartość 1, to zgodnie z warunkiem (7) proces $v$ może rozpocząć się dopiero po zakończeniu procesu $u$ - warunek (8) będzie zawsze spełniony. Jeżeli zmienna $y_{u, v}$ przyjmie wartość 0 , to zgodnie z warunkiem (8) proces $v$ musi zakończyć się przed rozpoczęciem procesu $u$ - warunek (7) będzie zawsze spełniony. Składnik $M \cdot\left(2-x_{u, r}-x_{v, r}\right)$ przyjmie bowiem wartość 0 tylko wtedy, gdy $x_{u, r}=1 \wedge x_{v, r}=1$, czyli gdy zarówno proces $u$, jak i $v$ będą realizowane przez wykonawcę $r$. Czas i koszt realizacji przedsięwzięcia nie mogą przekroczyć wielkości ustalonych zadeklarowanych w umowie (9) i (10), a koszty realizacji robót przez podwykonawców nie moga przekroczyć ustalonego kosztu granicznego (11). Zależności (12)-(15) służą do wyznaczenia terminów rozpoczęcia i zakończenia pracy brygad generalnego wykonawcy przy realizacji przedsięwzięcia. Pomimo że zależności (14) i (15) mają formę nierówności, pozwalaja na wyznaczenie poszukiwanych wartości ekstremalnych ze względu na postać funkcji celu (maksymalny termin zakończenia pracy brygady jest w funkcji celu minimalizowany, a termin minimalny rozpoczęcia jest maksymalizowany). Warunki (16)-(18) oraz (21) wprowadzono do modelu w celu linearyzacji zależności (1). Jeżeli zmienna $x_{j, r}=1$, wówczas zmienna $p_{j, r}$, zgodnie z zależnością (17) i (18), przyjmie wartość $s_{j}\left(p_{j, r} \leq s_{j} \wedge p_{j, r} \geq s_{j}\right)$. W przeciwnym przypadku przyjmie wartość 0 , zgodnie z zależnością (16) $p_{j, r} \leq 0$ i zależnością (21) $p_{j, r} \geq 0$. Zależności (19)-(23) stanowią warunki brzegowe modelu. 


\section{Przykład obliczeniowy i wyniki}

W celu weryfikacji poprawności modeli opracowane podejście selekcji podwykonawców i harmonogramowania ich pracy zastosowano do wyznaczenia wykonawców przykładowego przedsięwzięcia budowlanego. Analizowane przedsięwzięcie obejmuje budowę trzech obiektów i jest realizowane w systemie generalnego wykonawstwa.

Zależności kolejnościowe między poszczególnymi procesami (pakietami robót) oraz czasy i koszty wykonania poszczególnych procesów przez podwykonawców (ocenionych pozytywnie na etapie prekwalifikacji) i brygady $G W$, określone na podstawie oszacowań $G W$ i ofert podwykonawców, zamieszczono w tabeli 1 . Niektórzy wykonawcy mogą realizować kilka pakietów robót. W tabeli 2 wyszczególniono elementy niepustych zbiorów $J_{r}$ par procesów, które mogą być realizowane przez tego samego wykonawcę i które nie leżą na tej samej drodze w grafie.

Minimalny koszt realizacji (przy nieograniczonym czasie realizacji i koszcie

TABELA 1. Dane do przykładu

TABLE 1. Example datasets

\begin{tabular}{|c|c|c|c|c|c|}
\hline $\begin{array}{l}\mathrm{Nr} \\
\mathrm{No}\end{array}$ & $\begin{array}{l}\text { Obiekt } \\
\text { Object }\end{array}$ & $\begin{array}{l}\text { Numery procesów } \\
\text { bezpośrednio } \\
\text { poprzedzających } \\
\text { Numbers of direct } \\
\text { predecessors }\end{array}$ & $\begin{array}{l}\text { Podwykonawca/ } \\
\text { /brygada } G W \\
\text { Subcontrator/ } \\
\text { /crew of General } \\
\text { Contractor }(G C)\end{array}$ & $\begin{array}{l}\text { Czas realizacji } \\
\text { [dni] } \\
\text { Process duration } \\
\text { [days] }\end{array}$ & $\begin{array}{c}\text { Koszt realizacji } \\
{[1000 \text { PLN }]} \\
\text { Executing cost } \\
{[1,000 \text { PLN }]}\end{array}$ \\
\hline 1 & 2 & 3 & 4 & 5 & 6 \\
\hline \multirow{3}{*}{1} & \multirow{9}{*}{ I } & \multirow{3}{*}{-} & A & 20 & 90 \\
\hline & & & $\mathrm{B}$ & 18 & 110 \\
\hline & & & GW-1 & 17 & 100 \\
\hline \multirow{3}{*}{2} & & \multirow{3}{*}{1} & $\mathrm{C}$ & 25 & 100 \\
\hline & & & $\mathrm{D}$ & 20 & 120 \\
\hline & & & GW-2 & 20 & 110 \\
\hline \multirow{3}{*}{3} & & \multirow{3}{*}{2} & $\mathrm{C}$ & 45 & 150 \\
\hline & & & $\mathrm{D}$ & 40 & 160 \\
\hline & & & GW-2 & 42 & 155 \\
\hline \multirow{3}{*}{4} & \multirow{9}{*}{ II } & \multirow{3}{*}{-} & A & 12 & 50 \\
\hline & & & $\mathrm{B}$ & 10 & 55 \\
\hline & & & GW-1 & 11 & 52 \\
\hline \multirow{3}{*}{5} & & \multirow{3}{*}{6} & $\mathrm{C}$ & 15 & 49 \\
\hline & & & $\mathrm{D}$ & 12 & 55 \\
\hline & & & GW-2 & 14 & 50 \\
\hline \multirow{3}{*}{6} & & \multirow{3}{*}{7} & $\mathrm{C}$ & 25 & 70 \\
\hline & & & $\mathrm{D}$ & 30 & 65 \\
\hline & & & GW-2 & 33 & 72 \\
\hline
\end{tabular}


TABELA $1 \mathrm{~cd}$.

TABLE 1 cont.

\begin{tabular}{|c|c|c|c|c|c|}
\hline 1 & 2 & 3 & 4 & 5 & 6 \\
\hline \multirow{3}{*}{7} & \multirow{3}{*}{ III } & \multirow{3}{*}{$*$} & $\mathrm{~A}$ & 10 & 35 \\
\cline { 4 - 6 } & & & $\mathrm{B}$ & 9 & 40 \\
\cline { 4 - 6 } & & \multirow{3}{*}{10} & $\mathrm{GW}-1$ & 8 & 38 \\
\cline { 4 - 6 } 8 & & & $\mathrm{C}$ & 7 & 33 \\
\cline { 4 - 6 } & & & $\mathrm{D}$ & 7 & 38 \\
\hline & & & $\mathrm{GW}-2$ & 6 & 35 \\
\hline 9 & - & $3,8,11$ & - & 0 & 0 \\
\hline
\end{tabular}

TABELA 2. Elementy niepustych zbiorów $J_{r}$

TABLE 2. Elements of non-empty sets $J_{r}$

\begin{tabular}{|l|l|}
\hline $\begin{array}{c}\text { Podwykonawca/brygada } G W \\
\text { Subcontrator/Crew of General } \\
\text { Contractor }(G C)\end{array}$ & \multicolumn{1}{|c|}{$(u, v) \in J_{r}$} \\
\hline $\mathrm{A}, \mathrm{B}, \mathrm{GW}-1$ & $(1,4) ;(1,7) ;(4,7)$ \\
\hline $\mathrm{C}, \mathrm{D}, \mathrm{GW}-2$ & $(2,5) ;(2,6) ;(3,5) ;(3,6) ;(2,8) ;(3,8) ;(5,8) ;(6,8)$ \\
\hline
\end{tabular}

granicznym robót zlecanych podwykonawcom) wynosi 572 tys. PLN (czas realizacji 112 dni, koszt robót zleconych 572 tys. PLN). Żadna z brygad $G W$ nie została przydzielona do realizacji przedsięwzięcia. Minimalny czas realizacji przedsięwzięcia (przy nieograniczonym koszcie i koszcie granicznym robót zlecanych) wynosi 77 dni. W tym rozwiązaniu koszt realizacji wyniósł 628 tys. PLN, a koszt robót zleconych podwykonawcom osiagnął kwote 405 tys. PLN. W rozwiązaniu tym brygady $G W$ realizują następujące procesy: GW-1 proces 1 i 10 (przestój 0 dni), GW-2 proces 7, 11 (przestój 0 dni). Analiza wpływu wielkości $T, K$ i $K_{g G W}$ dostarcza dodatkowych informacji wspomagających decyzje $G W$ np. przy opracowywaniu oferty przetargowej.

Przyjęto, że czas realizacji przedsięwzięcia nie może być dłuższy niż 80 dni, koszt robót zleconych podwykonawcom nie powinien być większy niż 200 tys. PLN, a koszt realizacji przedsięwzięcia nie powinien przekroczyć kwoty 600 tys. PLN. Model matematyczny zagadnienia w przykładzie rozwiązano za pomoca programu LINGO 14.0.

Harmonogram realizacji przedsięwzięcia dla rozwiązania optymalnego przedstawiono na rysunku. W rozwiązaniu tym procesy $6,7,8$ i 10 są zlecane podwykonawcom. Koszt robót zleconych podwykonawcom wynosi 199 tys. PLN, koszt realizacji przedsięwzięcia wynosi 599 tys. PLN, a czas realizacji 80 dni. Brygady $G W$ pracują bez przerw. Analiza uzyskanych wartości w rozwiązanych przykładach potwierdza wiarygodność przyjętych założeń i poprawność modelu. 


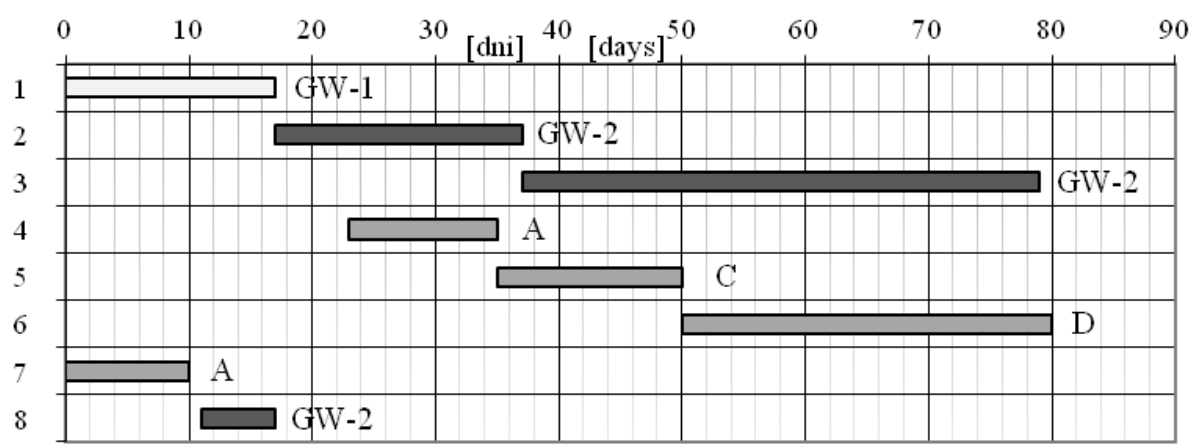

RYSUNEK. Harmonogram realizacji przedsięwzięcia - rozwiązanie optymalne przykładu FIGURE. Construction project schedule - optimal solution example

\section{Podsumowanie i wnioski}

Problem zapewnienia ciagłości pracy brygad realizujących kompleks operacji jest istotny przede wszystkim z punktu widzenia redukcji kosztów zatrudnienia brygad generalnego wykonawcy. Przy planowaniu przedsięwzięć budowlanych typu kompleks operacji należy korzystać zatem z metod harmonogramowania umożliwiających analizę modelu przedsięwzięcia nie tylko w funkcji czasu. Istotne jest również zaplanowanie efektywnego wykorzystania własnych zasobów z uwzględnieniem ograniczeń $\mathrm{w}$ ich dostępności oraz wzięcie pod uwagę konieczności współpracy z innymi przedsiębiorstwami przy podejmowaniu zleceń $\mathrm{i}$ ich realizacji. Generalne wykonawstwo to jeden z najbardziej popularnych w Polsce systemów realizacji przedsięwzięcia budowlanego. Podwykonawcy są zazwyczaj w stanie zrealizować specjalistyczne prace budowlane szybciej i mniejszym kosztem niż generalny wykonawca. Zlecanie robót podwykonawcom nie tylko robót specjalistycznych, ale również z konieczności, gdy nie można zrealizować przedsięwzięcia we własnym zakresie, w dzisiejszych czasach jest powszechną praktyka. Zaproponowany w artykule model matematyczny umożliwia ustalenie harmonogramu robót, a także dokonanie doboru wykonawców poszczególnych procesów spośród zasobów $G W$ i dostępnych podwykonawców. Model jest liniowo zależny, więc może być rozwiązywany z zastosowaniem dostępnego na rynku oprogramowania.

\section{Literatura}

Biruk, S. i Jaśkowski, P. (2009). The Work Continuity Constraints Problem in Construction Projects' Network Models. Archives of Civil Engineering, 55(1), 29-41.

Damci, A., Arditi, D. i Polat, G. (2013). Resource Leveling in Line of Balance Scheduling. Computer Aided Civil and Infrastructure Engineering, 28(9), 679-692.

Elbeltagi, E. i Ammar, M.A. (2001). Algorithm for Determining Controlling Path Considering Resource Continuity. Journal of Computing in Civil Engineering, 15(4), 292-298.

Georgy, M.E. (2008). Evolutionary Resource Scheduler for Linear Projects. Automation in Construction, 17(5), 573-583.

Grasso, B., Rasdorf, W. i Bridgers, M. (2008). Nature and Extent of Domestic Construction Program Outsourcing. Journal of Construc- 
tion Engineering and Management, 134(12), 1002-1010.

Harris, R.B. i Ioannou, P.G. (1998). Scheduling Projects with Repeating Activities. Journal of Construction Engineering and Management, 124(4), 269.

Nowicki, K. (1981). Organizacja i ekonomika budowy. Wrocław: Wydawnictwo Politechniki Wrocławskiej.

Tang, Y., Liu, R. i Sun, Q. (2014). Schedule Control Model for Linear Projects Based on Linear Scheduling Method and Constraint Programming. Automation in Construction, 37, 22-37.

Vanhoucke, M. (2006). Work Continuity Constraints in Project Scheduling. Journal of Construction Engineering and Management, 132(1), 14-25.

Vanhoucke, M. i Debels, D. (2007). The Discrete Time/Cost Trade-off Problem: Extensions and Heuristic Procedures. Journal of Scheduling, 10(4-5), 311-326.

Wang, W., Wang, X., Ge, X. i He, Y. (2013). Resource Continuity Constraints in Repetitive Project Scheduling. Journal of Information \& Computational Science, 10(17), 5619-5628.

Zhang, L., Zou, X. i Su, Z. (2013). GA Optimization Model for Time/cost Trade off Problem in Repetitive Projects Considering Resource Continuity. Applied Mathematics \& Information Sciences, 7(2), 611-617.

\section{Streszczenie}

Problem minimalizacji przestojów w pracy brygad generalnego wykonawcy w harmonogramowaniu przedsięwzięć budowlanych. Przedsiębiorstwa realizując przedsięwzięcia budowlane, dążą do uzyskania największego stopnia harmonizacji pracy angażowanych zasobów, co przejawia się w zapewnieniu ciągłej i równomiernej produkcji przy pełnym wykorzystaniu ich poten- cjału wykonawczego. W artykule przeanalizowano problem harmonizacji pracy brygad generalnego wykonawcy, realizujących procesy nierytmiczne, niecykliczne i niejednorodne przy założeniu deterministycznych warunków działania. Opracowano model matematyczny problemu minimalizacji przestojów w pracy brygad generalnego wykonawcy przy ustalonym w kontrakcie terminie zakończenia przedsięwzięcia i limicie kosztu jego realizacji, uwzględniając ograniczenia w dostępności brygad oraz możliwość zlecania robót podwykonawcom.

\section{Summary}

Minimisation of work gaps for general contractor crews in construction project scheduling. During executing of construction projects enterprises seek for high level of coordinating engaged resources. This seeking evinces in providing continuity and levelling production. It enables making of entire production capability. This paper analyses scheduling work of general contractor crews, which carry out unrhytmic, non-cyclic and inhomogeneous processes in deterministic conditions. The mathematical model of work gaps for general contractor crews in construction project scheduling is formulated. This model also counts crews availability limits, cost and time constraints and possibility of tasks outsourcing for subcontractors.

Authors' address:

Piotr Jaśkowski, Michał Tomczak

Politechnika Lubelska

Katedra Inżynierii Procesów Budowlanych

ul. Nadbystrzycka 40

20-618 Lublin, Poland

e-mail: p.jaskowski@pollub.pl m.tomczak@pollub.pl 